\title{
Prevalence of Intestinal Parasites in HIV Seropositive Patients Attending an Integrated Counselling and Testing Centre
}

\author{
Martha Zothansangi Chhangte ${ }^{1}$, Avani Koticha², Nayana Ingole ${ }^{3}$, Preeti Mehta ${ }^{4}$ \\ ${ }^{1}$ Department of Microbiology, Seth G. S. Medical College and KEM Hospital, Mumbai, Maharashtra, India. \\ ${ }^{2}$ Department of Microbiology, Seth G. S. Medical College and KEM Hospital, Mumbai, Maharashtra, India. \\ ${ }^{3}$ Department of Microbiology, Seth G. S. Medical College and KEM Hospital, Mumbai, Maharashtra, India. \\ ${ }^{4}$ Department of Microbiology, Seth G. S. Medical College and KEM Hospital, Mumbai, Maharashtra, India.
}

\section{ABSTRACT}

\section{BACKGROUND}

HIV infection is the most disastrous and invariably fatal disease. Its devastating effect is due to its relentless and eventually complete destruction of the immune system. As a result, people infected with HIV die not due to the virus itself, but rather due to plethora of opportunistic infections that characterize AIDS. Intestinal parasitic infections are a significant cause of morbidity and mortality in patients infected with HIV in which Diarrhoea is one of the most common clinical presentations. ${ }^{1}$ With this background, a prospective study was carried out to determine the prevalence of intestinal parasites in HIV seropositive patients attending an Integrated Counselling Testing Centre (ICTC) of a tertiary care hospital.

\section{METHODS}

A cross-sectional study was conducted in a tertiary care multispecialty teaching hospital for a period of one year. Stool specimens of 250 HIV seropositive patients above 18 years of age and belonging to all genders, were screened for intestinal parasites in the present study. The stool specimens submitted were processed using direct wet mounts, concentration technique of formol ether, sedimentation and saturated common salt solution, and permanent staining techniques using Modified Acid-Fast staining, Trichrome staining and Modified Trichrome staining methods.

\section{RESULTS}

The prevalence of intestinal parasites in HIV seropositive patients was found to be $27.6 \%(69 / 250)$. Protozoan parasites were predominant and were detected in $81.15 \%$ (56/69), followed by intestinal helminths in $11.59 \%(8 / 69)$ and coccidian parasites in $7.24 \%(5 / 69)$.

\section{CONCLUSIONS}

Intestinal parasites are a common source of infection in HIV seropositive patients. These patients are a threat not only to themselves but also to others in the community as well. Hence routine screening of all HIV seropositive patients is a must in order to prevent and reduce morbidity and mortality in the community.

\section{KEY WORDS}

Parasites, HIV Patients, Intestinal Parasitic Infections

\author{
Corresponding Author: \\ Dr. Martha Zothansangi Chhangte, \\ H. No. GE-59, Lawjynriew, \\ Nongthymmai, Shillong-793014, \\ Meghalaya, India. \\ E-mail: marthachhangte70@gmail.com
}

DOI: $10.14260 / j e m d s / 2020 / 198$

Financial or Other Competing Interests: None.

How to Cite This Article:

Chhangte MZ, Koticha A, Ingole $N$, et al. Prevalence of intestinal parasites in HIV seropositive patients attending an integrated counselling and testing centre. J. Evolution Med. Dent. Sci. 2020;9(12): 919-923, DOI: 10.14260/jemds/2020/198

Submission 08-01-2019,

Peer Review 26-02-2020,

Acceptance 04-03-2020,

Published 23-03-2020.

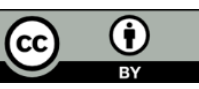




\section{BACKGROUND}

Infection due to Human Immunodeficiency Virus (HIV) is the most disastrous and invariably fatal disease due to its relentless and eventually complete destruction of the immune system. There is gradual depletion of CD $4+$ helper T cells. As a result, people infected with HIV die not due to the virus itself, but rather due to plethora of opportunistic infections that characterize AIDS. ${ }^{1}$ Intestinal parasitic infections are a significant cause of morbidity and mortality in patients infected with HIV, in which Diarrhoea is one of the most common presentation. Various studies worldwide have indicated that up to $90 \%$ patients infected with HIV in developing countries will suffer from diarrhoea at some point in time of which the vast majority are caused by parasites, especially in tropical countries like India.,2,3

The prevalence of intestinal parasites in HIV patients account for $30-60 \%$ in the developed nations and $50-90 \%$ in the developing nations.5,6 Studies have been carried out from various parts of India to determine the prevalence of intestinal parasites which ranges from $20-50 \%{ }^{2,3,4}$ In spite of the use of HAART in decreasing the incidence and severity of these parasitic infections, the problem of opportunistic infections especially diarrhoea, continues to plague developing countries like India.7,8 The treatment varies with each type of the parasite infecting the HIV patient. Hence, it is absolutely essential to precisely identify the causative agent so that appropriately targeted therapy could be initiated, and complications can be prevented.7,8

With this background, a prospective study was carried out to determine the prevalence of intestinal parasites in HIV seropositive patients attending an Integrated Counselling Testing Centre (ICTC) of a tertiary care hospital.

\section{METHODS}

A cross-sectional study was conducted in a tertiary care multispecialty teaching hospital for a period of one year after obtaining permission from the Institutional Ethics Committee. A total of 250 HIV patients above 18 years of age and belonging to all genders and tested positive for HIV antibodies were recruited for the present study. The sampling was done as follows: Pre-test counselling was done for the patients coming voluntarily or referred by the clinicians for HIV antibodies testing to Integrated Counselling and Testing Centre (ICTC). Written informed consent was taken for HIV antibodies testing and subsequently tested as per NACO guidelines. At the time of pre-test counselling, the importance of the present study was explained to these patients. Those who were willing to disclose their HIV test report and also agree to participate were enrolled for the present study. A separate written informed consent was taken from each participant for the study

A leak proof, dry mouth container with identification number along with proper instructions for collection and transport of stool specimen was given to each participant. When the patients came for post-test counselling and for collecting their report on HIV testing to ICTC, they submitted a single fresh stool specimen. The HIV status of each patient was kept confidential by the counsellor as well as by the investigator. Out of the total 2500 patients attending the ICTC in one year, it was found that the HIV seropositivity was $10 \%$ and the prevalence of intestinal parasites was found to be $60 \%$. Considering these facts, the sample size was calculated using the following formula-

$N=\frac{Z^{2} P(1-p)}{D^{2}}$

Where $\mathrm{n}=$ sample size, $\mathrm{Z}=$ constant of $1.96, \mathrm{P}=$ prevalence, $\mathrm{D}=$ precision

Sample size $=250$

The stool samples were processed using direct wet mounts, concentration technique of formol ether sedimentation and saturated common salt solution and permanent staining techniques using Modified Acid-Fast staining, Trichrome staining and modified trichrome staining methods. The results of all the tests were observed, interpreted and recorded.

\section{RESULTS}

In the present study, the prevalence of intestinal parasites in HIV seropositive patients was found to be $27.6 \%(69 / 250)$ and the prevalence of intestinal parasites was found to be more common among males (19.2\%) than females $(08.4 \%)$ (table 1). Protozoan parasites were predominant and were detected in $81.15 \%$ (56/69), followed by intestinal helminths which was $11.59 \%(8 / 69)$ and coccidian parasites $7.24 \%$ (5/69) (table 2).

\begin{tabular}{|c|c|c|c|}
\hline & $\begin{array}{c}\text { Parasites } \\
\text { Detected (\%) }\end{array}$ & $\begin{array}{c}\text { Parasites not } \\
\text { Detected (\%) }\end{array}$ & Total (\%) \\
\hline Males & $48(19.2 \%)$ & $115(46.0 \%)$ & $166(66.4 \%)$ \\
\hline Females & $21(08.4 \%)$ & $66(26.4 \%)$ & $84(33.6 \%)$ \\
\hline Total & $69(27.6 \%)$ & $181(72.4 \%)$ & 250 \\
\hline \multicolumn{3}{|c|}{$\begin{array}{c}\text { Table 1. Prevalence of Intestinal Parasites in } \\
\text { HIV Seropositive Patients (n=250) }\end{array}$} \\
\hline
\end{tabular}

\begin{tabular}{|c|c|c|}
\hline & Parasite & Number (\%) \\
\hline \multirow[t]{4}{*}{ Common Intestinal Protozoa } & $\begin{array}{l}\text { Cysts of Entamoeba } \\
\text { histolytica/dispar }\end{array}$ & $24(34.78 \%)$ \\
\hline & Cysts of Entamoeba coli & $8(11.59 \%)$ \\
\hline & Cysts of Giardia lamblia & $7(10.14 \%)$ \\
\hline & Cysts of Blastocystis hominis & $17(24.63 \%)$ \\
\hline Total Protozoa & & $56(81.15 \%)$ \\
\hline \multirow[t]{3}{*}{ Helminths } & Eggs of Ascaris lumbricoides & $6(8.69 \%)$ \\
\hline & $\begin{array}{l}\text { Larvae of Strongyloides } \\
\text { stercoralis }\end{array}$ & $1(1.44 \%)$ \\
\hline & Eggs of Hymenolepis nana & $1(1.44 \%)$ \\
\hline Total Helminths & & $8(11.59 \%)$ \\
\hline \multirow[t]{3}{*}{ Coccidian Parasites } & $\begin{array}{c}\text { Oocysts of Cryptosporidium } \\
\text { species }\end{array}$ & $1(1.44 \%)$ \\
\hline & Oocysts of Cystoisospora belli & $3(4.34 \%)$ \\
\hline & Oocysts of Cyclospora species & $1(1.44 \%)$ \\
\hline Total Coccidia & & $5(7.24 \%)$ \\
\hline $\begin{array}{c}\text { Total No of Patients Detected to } \\
\text { Have Intestinal parasites }\end{array}$ & & 69 \\
\hline \multicolumn{3}{|c|}{$\begin{array}{c}\text { Table 2. Intestinal Parasites Detected in } \\
\text { HIV Seropositive Patients }(n=69)\end{array}$} \\
\hline
\end{tabular}

\section{DISCUSSION}

The attack on the immune system by HIV virus leading to decrease in the CD4 count leads to irreversible breakdown of 
the immune defence mechanism making the individual become vulnerable to acquire opportunistic infections. ${ }^{1}$ These opportunistic infections could be caused by any organism including bacteria, fungi, viruses and parasites. Diarrhoea is the most common presentation in HIV infected individuals, most commonly caused by intestinal parasites which may include Cryptosporidium species, Cystoisospora belli, Microsporidia species, Giardia lamblia, Entamoeba histolytica and Strongyloides stercoralis. ${ }^{1}$

The clinical spectrum caused by these parasites particularly among HIV positive patients leads to gradual debilitation through dehydration, metabolic abnormalities and even death. 6,2 The diagnosis of these parasites mainly lies in their demonstration in stool samples of the HIV affected individuals. Hence laboratory diagnosis is highly important for the evaluation of these patients which may provide guidelines in their better management and prevention of any complications that may occur. Studies have shown that the frequency of intestinal parasitic diseases poses a great threat to the community, requiring periodic screening for these parasites. ${ }^{7}$ Thus, the present study was undertaken to determine the prevalence of intestinal parasites in HIV infected individuals attending an ICTC of a Tertiary Care Hospital to highlight the importance of screening of HIV infected individuals for the presence of intestinal parasites which is important in reducing the morbidity and mortality in these patients. The prevalence of intestinal parasites in HIV seropositive individuals in the present study was found to be $27.6 \%(69 / 250)$ (table 1).

A higher prevalence could have been obtained if the total number of stool specimens obtained from each patient had been more than one. A similar finding has been reported by Nilesh et al and Desh at al.1,3 Similarly, studies carried out in other parts of the world also demonstrated a more or less similar prevalence.9,10 A very high prevalence of $60.9 \%$ has been reported by Nitya et al in India in 2012 in HIV seropositive patients. ${ }^{11}$ The moderate to high prevalence of intestinal parasites in HIV seropositive patients reported by various researchers as well as that of the present study could be attributed to the tropical climate of India and otherwise a high parasite density in the general population. Such climate in addition to lack of safe drinking water, poor hygienic and sanitary conditions and over- crowding could favour intestinal parasites to thrive in the environment.

Of the $27.6 \%$ parasites detected (Table 2), intestinal protozoa predominated the list which was $81.15 \%$, followed by intestinal helminths (11.59\%) and coccidian parasites (7.24\%). Among the protozoan parasites the most common parasite found to be was Entamoeba histolytica/dispar (34.78\%) followed by Blastocystis hominis (24.63\%), Entamoeba coli (11.59\%) and Giardia lamblia (10.14\%). There is difficulty in determining the clinical significance of Entamoeba histolytica in stool as its cyst is similar to Entamoeba dispar morphologically and hence cannot be differentiated. As per the literature, about $90 \%$ of Entamoeba histolytica reported is actually Entamoeba dispar which is known to be non-pathogenic. Hence to differentiate the two, molecular analysis or ELISA test needs to be performed on stool specimens. However, these tests are not feasible in routine parasitology laboratories, hence careful history of the patient needs to be taken and if stool specimen is found to have Entamoeba histolytica, treatment for the same needs to be initiated. ${ }^{12}$ The prevalence of Entamoeba histolytica/dispar in the present study was found to be $34.78 \%$ which is similar to the findings seen by Amancio et al in 2012 in which a prevalence of $38.5 \%$ was seen. ${ }^{7}$ The high prevalence of Entamoeba histolytica/dispar in our study may be explained by the fact that there is favourable climatic condition for survival of cysts outside the human host and factors contributing to its transmission is also favourable. Intestinal amoebiasis may also be asymptomatic in many cases. ${ }^{12}$ Blastocystis hominis is a unicellular, eukaryotic protozoan parasite transmitted through ingestion of contaminated water or food.13 Infection with this parasite is believed to occur more in immunocompromised patients and immigrants travelling from developing countries. ${ }^{14}$

The prevalence of Blastocystis hominis in the present study was found to be $24.63 \%$. A similar finding seen by Amancio et al in 2012 in which a prevalence of $23.0 \%$ was reported. ${ }^{7}$ Lower prevalence of $1.0 \%$ has been reported by Ebenezar et al in 2014 and $4.4 \%$ prevalence has been reported by Mohammad et al in 2004.15,16 The high prevalence in the present study could be attributed to high parasitic load in the community and the difference in the prevalence could be due to climatic and geographical factors. Entamoeba coli are believed to be single-celled parasites, non-pathogenic and do not harm the body even in a person with weak immune system. ${ }^{13}$ A prevalence of $11.59 \%$ was found in our study. Other studies have also found Entamoeba coli in their studies which could mean that it could be significant in HIV seropositive patients. A higher prevalence of $21.42 \%$ was reported by Celine et al in $2013 .{ }^{17}$ However, a lower prevalence of $3.9 \%$ as compared to our study was reported by Mohammad et al in 2004 and 1\% by Ebenezar et al in 2014.15,16

Entamoeba coli though a non-pathogenic amoeba is an important bioindicator. Its demonstration in stool specimens indicates presence of unhygienic practices among patients which increases the faeco-oral transmission of other infectious agents. There has been a report in which increased transmission of Vibrio cholerae is demonstrated in patients who already had Entamoeba coli in their stool specimens. However, we need a more comprehensive study to corroborate this finding. ${ }^{12}$ Giardia lamblia cysts are protected by an outer shell that allow it to survive outside the body for long periods of time and also makes it tolerant to chlorine disinfection and as few as 10-25 cysts can initiate an infection. ${ }^{13,18}$ Giardia lamblia was detected in $10.14 \%$ of the cases in the present study. Similar findings were reported by Oguntibeju et al in 2006 with prevalence of $8.3 \%$ and Mohammad et al in 2004 with a prevalence of 7.3\%.16,19 The prevalence of Ascaris lumbricoides has been reported to be $8.69 \%$ in our study. A similar finding of $7.7 \%$ was reported by Amancio et al. ${ }^{7}$ However, a very high prevalence of $30.8 \%$ was reported by Getachew et al in 2004.20 The low prevalence of the present study could be attributed to certain environmental factors. Larvae of Ascaris lumbricoides develop only in moist soils, the high temperature where the study was carried out probably does not allow the eggs of parasites to survive in dry soil for sufficient period for their growth and maturation. Industrialization and construction work in cities, cemented pavements and sanitary latrines have reduced the occurrence of outdoor defecation. This might be responsible for the low prevalence of helminths in our study. Most of the 
studies on association of strongyloidiasis in HIV patients have reported a very low prevalence of Strongyloides stercoralis. A similar observation was also made in the present study. Larvae of Strongyloides stercoralis was found in one case giving its prevalence to be $1.44 \%$. Almost similar prevalence of $0.25 \%$ was reported by Celine et al in 2013.17

Prevalence of strongyloidiasis in other immunecompromised states is comparatively high than in HIV. It has been postulated that the low prevalence of this disease in HIV infected patients could be attributed to the disease progression of HIV itself. Strongyloides stercoralis needs a good immune status to progress from intestinal phase to hyper infection syndrome to disseminated strongyloidiasis. Thus, advanced immunosuppression will certainly hinder the dissemination to various organs as well as halt its multiplication and maturation to be detected in stool samples. ${ }^{21}$ One case of Hymenolepis nana was reported with a prevalence of $1.44 \%$ in our study. A study carried out by Mohammad et al in 2004 reported a prevalence of $0.9 \% .{ }^{16}$ Individuals with HIV/AIDS are not especially prone to helminthic infections and these values are similar to the values found in HIV seronegative individuals. Five cases of coccidian parasites were detected in the present study giving its prevalence to be $7.24 \%$. Out of these five coccidian parasites, three were Cystoisospora belli (4.34\%), one was Cryptosporidium species (1.44\%) and one was Cyclospora species (1.44\%). A study conducted by Manish et el in 2013 reported its prevalence of $34.7 \%$ in HIV seropositive patients. ${ }^{22}$ The prevalence of Cystoisospora belli in the present study was $4.34 \%$. This finding is almost similar to that reported by Ogubtibeju et al in 2006 with a prevalence of $3.3 \% .{ }^{19} \mathrm{~A}$ higher prevalence of $35 \%$ was however reported by Desh et al in 2013. ${ }^{3}$ our patients with Cystoisospora were not on any co-trimoxazole prophylaxis.

A prevalence of Cryptosporidium species in the present study was $1.44 \%$. A similar prevalence of $2 \%$ was reported in 2013 by Anand et al while a prevalence of $2.53 \%$ was reported by Celine et al in 2013.17,23 A higher prevalence of $10 \%$ was reported by Oguntibeju et al in 200519 The prevalence of Cyclospora species was found to be $1.44 \%$ in our study. Prevalence of $3.92 \%$ was reported in 2013 by Rivero et al in Venezuela among the HIV seropositive patients. ${ }^{24} \mathrm{~A}$ case report of Cyclospora cayetanensis was also reported by Khadijeh et al in 2014 from Tehran in a patient with HIV. ${ }^{25}$ Opportunistic parasites such as Cryptosporidium parvum, Cyclospora cayetanensis and Cystoisospora belli are a common feature in HIV/AIDS persons especially when the CD4+ T cell counts are below 200 cells/ $\mu{ }^{26}$ These parasites still remain the leading causes of diarrhoea and leading causes of infection in immune-compromised patients. The differences in the prevalence in various studies could be due to different geographic regions, environmental conditions, populations, parasitic burden in the community and diagnostic methods.

\section{CONCLUSIONS}

Intestinal parasites are a common source of infection in HIV seropositive patients. These parasites may cause asymptomatic or symptomatic infections in the affected individual. Symptomatic patients often present to the clinician early and hence diagnosed and treated often immediately. But there are still a great number of patients who are asymptomatic and whose infection remains undiagnosed. These patients are a threat not only to themselves but also to others in the community as well. Hence routine screening of all HIV seropositive patients is a must in order to prevent and reduce morbidity and mortality in the community.

\section{REFERENCES}

[1] Chavan NS, Chavan SN. Intestinal parasitic infections in HIV infected patients. Int J of Current Microbiol and Applied Sciences 2014;3(2):265-70.

[2] Kulkarni SV, Kairon R, Sane SS, et al. Opportunistic parasitic infections in HIV/AIDS patients presenting with diarrhoea by the level of immunosuppression. Indian J Med Res 2009;130(1):63-6.

[3] Singh DD, Singh V, Singh R, et al. Prevalence of opportunistic intestinal parasite infections in HIV positive population of Central India region. South Asian J Exp Biol 2013;3(Spec. Iss 6):330-4.

[4] Desai NT, Sarkar R, Kang G. Cryptosporidiosis: an underrecognized public health problem. Tropical Parasitology 2012;2(2):91-8.

[5] National Aids Control Organisation, Ministry of Health \& Family Welfare, Government of India. National Guidelines for HIV testing. July 2015[cited 21 Apr 2016]. http://www.naco.gov.in/sites/default/files/

[6] Chakraborty N, Mukherjee A, Santra S, et al. Current trends of opportunistic infections among HIVseropositive patients from Eastern India. Japanese Journal of Infectious Diseases 2008;61(1):49-53.

[7] Amâncio FAM, Pascotto VM, Souza LR, et al. Intestinal parasitic infections in HIV/AIDS patients: epidemiological, nutritional and immunological aspects. Journal of Venomous Animals and Toxins including Tropical Diseases 2012;18(2):225-35.

[8] Abaver DT, Nwobegahay JM, Goon DT, et al. Prevalence of intestinal parasitic infections among HIV/AIDS patients from two health institutions in Abuja, Nigeria. African Health Sciences 2011;11(Suppl 1):S24-7.

[9] Guk SM, Seo M, Park YK, et al. Parasitic infections in HIVinfected patients who visited Seoul National University Hospital during the period 1995-2003. The Korean Journal of Parasitology 2005;43(1):1-5.

[10] Vyas N, Pathan N, Aziz A. Enteric pathogens in HIVpositive patients with diarrhoea and their correlation with CD4+ T-lymphocyte counts. Tropical Parasitology 2012;2(1):29-34.

[11] Faulkner CT, Garcia BB, Logan MH, et al. Prevalence of endoparasitic infection in children and its relation with cholera prevention efforts in Mexico. Revista Panamericana de Salud Pública 2003;14(1):31-41.

[12] Centers for Disease Control and Prevention. Alphabetical index of parasitic diseases. https://www.cdc.gov/parasites/az/index.html

[13] Suh KN, Kozarsky P, Keystone JS. Cyclospora cayetanensis, Isospora belli, Sarcocystis species, Balantidium coli and Blastocystis hominis. In: Mendel G, Bennett J, Dolin R, eds. Principles and practice of 
infectious diseases. $7^{\text {th }}$ edn. Philadelphia: Elsevier/Churchill Livingstone 2009: p. 3566-7.

[14] Jegede EF, Oyeyi ETI, Bichi AH, et al. Prevalence of intestinal parasites among HIV/AIDS patients attending Infectious Disease Hospital Kano, Nigeria. Pan African Medical Journal 2014;17:295.

[15] Zali MR, Mehr AJ, Rezaian M, et al. Prevalence of intestinal parasitic pathogens among HIV-positive individuals in Iran. Jpn J Infect Dis 2004;57(6):268-70.

[16] Nkenfou CN, Nana CT, Payne VK. Intestinal parasitic infections in HIV infected and non-infected patients in a low HIV prevalence region, West-Cameroon. PLoS One 2013;8(2):e57914.

[17] Hill DR, Nash TE. Giardia lamblia. In: Mendel G, John Bennett J, Dolin R, eds. Principles and practice of infectious diseases. $7^{\text {th }}$ edn. Philadelphia: Elsevier 2010: p. 3527-32.

[18] Oguntibeju 00. Prevalence of intestinal parasites in HIVpositive/AIDS patients. Malays J Med Sci 2006;13(1):6873.

[19] Hailemariam G, Kassu A, Abebe G, et al. Intestinal parasitic infections in HIV/AIDS and HIV seronegative individuals in a teaching hospital, Ethiopia. Japanese Journal of Infectious Diseases 2004;57(2):41-3.

[20] Schmidlin T, Hurlimann E, Silue KD, et al. Effects of hygiene and defecation behavior on helminths and intestinal protozoa infections in Taabo, Cote d'Ivoire. PLoS One 2013;8(6):e65722.
[21] Viney ME, Brown M, Omoding NE, et al. Why does HIV infection not lead to disseminated strongyloidiasis? Journal of Infectious Diseases 2004;190(12):2175-80.

[22] Mathur MK, Verma AK, Makwana GE, et al. Study of opportunistic intestinal parasitic infections in human immunodeficiency virus/acquired immunodeficiency syndrome patients. Journal of Global Infectious Diseases 2013;5(4):164-7.

[23] Janagond AB, Sasikala G, Agatha D, et al. Enteric parasitic infections in relation to diarrhoea in HIV infected individuals with CD4 $\mathrm{T}$ Cell counts $<1000$ Cells/ $\mu \mathrm{l}$ in Chennai, India. Journal of Clinical and Diagnostic Research 2013;7(10):2160-2.

[24] Rivero-Rodríguez Z, Hernández A, Bracho Á, et al. Prevalence of intestinal microsporidia and other intestinal parasites in HIV positive patients from Maracaibo, Venezuela. Biomedica 2013;33(4):538-45.

[25] Khanaliha K, Mohebali M, Davoudi S, et al. Detection of emergence cyclospora cayetanensis in a HIV+/AIDS patient with Diarrhea from Tehran: a case report. Iranian Journal of Public Health 2015;44(6):865-8.

[26] Nsagha DS, Njunda AL, Assob NJC, et al. Intestinal parasitic infections in relation to $\mathrm{CD} 4+\mathrm{T}$ cell counts and Diarrhea in HIV/AIDS patients with or without antiretroviral therapy in Cameroon. BMC Infectious Diseases 2016;16:9. 